\title{
Nature between fact and fiction: A note on virtual reality
}

\author{
Svend Erik Larsen \\ Department of Comparative Literature, Aarhus University \\ Langelandsgade 139, DK-8000 Aarhus C, Denmark \\ e-mail: litsel@hum.au.dk
}

\begin{abstract}
The paper places the trendy notion of virtuality and virtual reality in a conceptual and historical context that makes it useful in a semiotic perspective. Virtuality is connected with the classical notion of fictionality, in its meaning of both invention and deception. Historically an active, a passive, and a neutral version of the concept can be distinguished. The notion is reinterpreted as a variant of the semiotic processes of deixis. In relation to nature - scenarios, prognoses, hypotheses, etc. - virtuality is seen as a means of anchoring the human subject in nature instead of constructing a nonreal universe separated from it.
\end{abstract}

\section{Fact, fiction, and nature}

Nature is part of our world of experience and therefore a material fact. On the other hand, nature can never be exhaustively accounted for in any experience, is it individual or shared, immediate or accumulated, instantaneous or mediated. Therefore, an essential and not just accidental part of our relationship to nature is that there is always a beyond any sensual experience that can only be grasped in symbols or in a symbolic activity by which we produce nature as a conceptual complex or just as an image. What we experience is always both experienced as something and imagined as something, whether the context be aesthetic, mythological, scientific, agricultural, ecological, etc. The goal of some approaches is to make experience and imagination meet in a synthesis - reality shall conform with the theoretical models of it; the goal of others is to maintain the opposition. Imagination tran- 
scends and deny the material experience in favor of a larger cosmological totality. To put it briefly, one might say that nature, in any context, is always both fact and fiction or rather always positioned between the two; in short: nature is always part of some process of semiosis.

In this general sense, fiction or fictionality does not only refer to a world of literary imagination. A brief glance at literature may give us an idea of its general meaning. Latin fingo both means 'I deceive' and 'I invent'. The opening of Honoré de Balzac's novel Illusions perdues (1837-1844) tells us that the events of the novel take place before the Standford printing press was invented. How can he talk sensibly about things that are not yet there? It is a reality for us and the narrator, but a mere illusion for the characters or just not conceivable for them. The simple piece of information accentuates the difference between two worlds with a different ontological status.

Another chapter, opening the second part of the same novel, relates to us that "neither Lucien, nor Mme de Bargeton, neither Gentil, nor Albertine [...] ever talked about the events on this journey to Paris". The narrator does not say anything about it either. Here, the fiction is construed in such a way as to points to something existing for the characters only, but which is also conceivable for us who know that Paris is a city on the map, although we will never come to know what happened during this tour. The reality to which "our" Paris belongs cannot provide us with any supplementary information. The tacit events are entirely undefined in the fictitious universe as well as in ours, but not in the same way.

Fictionality is a way of both separating and unifying different worlds that exist under different ontological conditions. It allows both to invent a world from a different perspective and at the same time to deceive the agents in one world when facts are presented according to the conditions of the other. Thereby a third world is constructed in which the questions of invention and deception are formulated and answers may be suggested. In this sense, literature and scientific enterprise are not essentially different, but they operate under different conditions regarding the methodology and validity of questions and answers, of invention and deception.

Fictionality is a semiotic means of enlarging or reducing the number and kinds of worlds we are faced with and of increasing or reducing the conditions on which they exist. From this perspective, fictionality is not a monolithic notion of artistic creation, but a general feature of the language-conditioned semiotic activity of humans. The 
analytical potential of fictionality becomes apparent if we see it in relation to the contexts in which the construction of alternative worlds takes place and if we consider the oppositions that define the specific position the fictional context. From this contextualized position also follows that there are specific limits to the worlds of fiction, depending on the context and on the conditions which allow the worlds to be distinguished. From a semiotic perspective, three relevant contexts are shown in Figure 1.

\begin{tabular}{|c|c|c|}
\hline CONTEXT & $\begin{array}{c}\text { DEFINING } \\
\text { OPPOSITION }\end{array}$ & $\begin{array}{c}\text { CONDITION/ } \\
\text { LIMIT }\end{array}$ \\
\hline referential & real/nonreal & Human experience \\
\hline media specific & $\begin{array}{c}\text { Immediate/ } \\
\text { Constructed }\end{array}$ & Expressibility \\
\hline communicative & $\begin{array}{c}\text { Reliable/ } \\
\text { Nonreliable }\end{array}$ & mutual understanding \\
\hline
\end{tabular}

Figure 1. Defining contexts of alternative worlds.

In a referential context, the basic defining opposition of fictionality holds between reality and nonreality, whereas in a media specific context, the basic defining opposition is that between immediacy and construction. When fictionality is placed in a communicative context, the defining opposition holds between reliability and nonreliability. In these three contexts, fictionality is positioned in the domains of nonreality, construction, and nonreliability.

Therefore, in a referential context, fictions reduce or enlarge the kind and number of worlds we are engaged in, according to the limits of human experience. For example, in the case of Balzac, the reference to the Standford printing press is an experience in our own, but not in the fictionally constructed universe. In a media specific context, fictions reduce or enlarge the kind and number of worlds we are engaged in according to the limits of the expressibility of the various media involved. For example, in the case of Balzac, the narrator remains silent vis-à-vis the readers, who are never to know about the details of the journey of which the fictional characters are perfectly well informed. Finally, in a communicative context, fictions reduce or enlarge the kind and number of worlds we are engaged in on the conditions of the limits of mutual understanding. In our example from 
Balzac, the narrator remains silent, but we imagine easily the troubles and embarrassments of the journey and why the characters remain silent. On the other hand, we also realize that neither the narrator nor the characters are entirely reliable because we will never be able to know whether they hide details from us. Fictions are hence not simply nonreal, constructed, and nonreliable, but they are semiotic constructs that allow us to discuss conditions and limits of human experience, expressibility, and mutual understanding.

This is why the construction of fiction is useful and even necessary when our relationship to nature is concerned. Nature is often supposed to transcend or simply do away with the various oppositions and conditions and, particularly, their context dependence. It seems as if nature goes beyond any human context, but this is not so, at least not any more. Nature does not state unambiguously what reality beyond human experience really is; nor does it offer a self-evident presence beyond any particular medium of expression or an immanent meaning beyond any communicative understanding.

Thus, in the realm of reference it is useless to distinguish between an earthquake and the melting down of the Chernobyl nuclear plant: the size and the consequences of the events are of the same scale independently of the degree of human intervention before, during, and after the fatal event. Whether released by humans or not, the nuclear process follows its own course. As far as the medium is concerned, the electronic media has blurred the basic difference between what is constructed and nonconstructed, at the level of highly sophisticated landscape scenarios, surgery equipment related to our bodies, laboratory simulations related to the terrestrial or planetary environment, as well as at the level of everyday self-perpetuating media constructed pseudo-events.

Finally, as to communication, the suggestive metaphor of a hole in the catchy term of the "the ozone hole" - like a hole in the roof that needs repair - is an example of what can be communicated convincingly to a large public. However, this metaphor has nothing to do with the selected chemical data referred to and listed in media specific digitalized messages received from the measurement technology by which the details of the ozone concentration and location in the atmosphere are defined more precisely. Such data cannot be deciphered by any single lay person or expert nor the details of the inseparably intertwined politico-scientific-technological criteria for the selection of ozone as a phenomenon most relevant among other possible natural deviations from a hypothetically balanced situation. 
If nature in earlier times transgressed the dichotomies of real vs. nonreal, immediate vs. constructed, and reliable vs. nonreliable in the domain of the real, the immediate, and the reliable, one might say today that nature blows up these dichotomies at their opposites. It is because of nonreal constructions of a not entirely reliable character that we can relate to nature under modern conditions. The Rio convention on the environment of 1992, with its arguments based on mixed natural-political criteria and its ensuing principles for nature protection and political decision making, is the first major global sign of nature as factual fiction or fictional fact. At any rate, nature is in no way outside the game of contextualization, fictionality, and constructibility. Basically, the changing place of nature in human reality since the 20 th century has been a reason why we are forced to reconsider what fictionality and constructibility is or might be. In a cluster of relevant terms the notion of virtuality has been the most enticing in this reconsideration of the reality of nature.

\section{Virtualities}

In the Western World, any kid between 8 and 80 will relate virtual reality to some kind of electronic gadget with gloves and glasses and similar outer space type of outfit, something that is not really real. Hence, it might be inferred that virtual nature is fake nature, theme park nature. Analogically, virtual cities may be taken as utopian prospects, Piranesi drawings, futuristic urban planning never to be realized. Let me try to suggest a different interpretation of virtuality in line with the above reflections on fictionality.

The term 'virtual reality' has first been used in American English, but even without translation, it has entered other languages, for instance, my own mother tongue, Danish, and this is not by chance.

First, the technological capacity of the US to produce the virtual reality equipment as a popular toy as well as a powerful tool is evident - the term and the thing was born together in the US, like jeans and coke.

Second, words like 'virtual', 'virtuality', or 'virtually' have a much more widespread use in everyday English than in other European languages, where similar words are also part of the vocabulary, as for instance in French, but on a narrower semantic basis as a comparison with Webster's or Roget's Thesaurus with any French Dictionnaire de 
synonymes will show. This linguistic fact explains why we, in English, so easily construct a virtually - as it were - endless chain of terms like 'virtual nature', 'virtual cities', 'virtual water', 'virtual landscape', 'virtual sex', 'virtual space' - all with virtual reality as the hidden point of reference. Here, we have an inflated semantics that forces us to ask whether we are dealing with the same type of virtuality or reality in all cases. What are the consequences if we are, or if we are not? Does it matter to be concerned with historical semantics, or is it just an example of academic acrobatics?

Third, constructive or playful approaches to reality seen as natural to humans is a fundamental idea in Western thought, based on a rich stock of dichotomies such as actual vs. virtual, real vs. fictional etc. Since Plato and Aristotle we have either been denigrating or praising the second term of the opposition but rarely, if ever, we have taken a neutral stance to it. This is not the case in all cultures, not even in all high-tech societies. In Japan, e.g., nature is seen as a constructed aesthetic phenomenon expressing emptiness quite different from the spontaneous European sublime expressing trans-human values.

Therefore, my point here will be that it is important to consider semantics and history, especially in our own culture, both for our conceptual and practical relation to our environment.

The notion of virtuality is opposed to the one of actuality, which we have inherited from the medieval scholastics, who shaped it by their endless ruminations on the modes and appearances of reality. The opposition in Greek was the one between dynamis and energeia. I will distinguish between three meanings of virtuality which today seem to grow apart to the point of confusion. Even in the innocent use of the word 'virtual', 'virtuality', or 'virtually', these meanings play around with us both in everyday communication and in scientific or otherwise consciously elaborated contexts. I will dub the three meanings, or rather three argumentative strategies, the active, the passive and the neutral meanings.

\section{Active virtuality}

Virtuality most often means 'the power, the capacity of something to be actual'. This is the active sense. The basic assumption is that the identity of a phenomenon relies on the fact that it has some immanent formative power enabling it to move from one state to another, which 
is more appropriate for this phenomenon and makes it more fully developed. In classical philosophy, this engendering virtuality used to be identified with the form of the thing, its inherent possibility to reach a kind of final state of being fully actualized. The fully grown tree would actualize the virtuality of the seed (analogically, in the case of human beings, we refer to their virtues).

Hence, the actual state is not different from the virtual one, but it is the effect of the virtual power. The actual makes the virtual visible or palpable, but it does not transgress it. The virtual form is still there also in the actual state. Otherwise, there would be no actuality. They are levels of the same reality. There is no temporal difference between virtual and actual. We do not have first the virtual then the actual. Virtuality is a timeless process releasing power, whereas actualization is a process.

From Greek and Roman philosophy - for instance from the teleology in Cicero's De natura deorum (45 BC) - this way of thinking was easily integrated in Christian thought culminating in Scholasticism, virtuality being basically identified with the creative power of God inherent in everything created as its purpose. The virtual and the actual are similar but not identical phenomena, and always co-existing and mutually interdependent and - particularly — equally real and immediately natural.

When Aristotle describes the good city in the seventh book of his Politica (ca. 350 BC), he outlines the features of the right place to build a city. Such a place is given by nature as a virtual city-place, and it remains such a place the more the city is actualized as a good city. The place allows for a city. If the urban development destroys the virtuality of the place, the actual city will crumble, as Augustine claimed for Rome in De civitate dei (ca. $425 \mathrm{AD}$ ). The whole notion of genius loci in relation to nature is related to this aspect of virtuality.

\section{Passive virtuality}

Virtuality has a passive meaning, too, also handed down from classical philosophy. Matter, substratum, hypokeimenon, and such concepts refer to aspects of reality without an inherent form or an active formative capacity, without dynamis. Matter in this sense is void of forms and therefore ready to receive any form that may turn it into things with an identity. It is undetermined and therefore virtually everything 
else. 'Virtual' means that matter is a tabula rasa. Here the relation between actual and virtual is different from active virtuality. In the former case, the virtual is a permanent immanent determination of the actual, in the latter, actualization makes virtuality disappear, often in degrees - certain things are more actual than others. The tabula rasa is more or less filled out and is no longer rasa. When things are actual, they are no longer virtual. Therefore actuality and virtuality are fixed properties of something, not, as in the case of active virtuality, stages of an ongoing process. The virtual and the actual are mutually exclusive opposites.

In his Novum Organon (1620), Francis Bacon claims that nature has no power to become actual and thus to become real nature without human intervention. Humans release the virtuality of nature, turn it into actual and real nature in order to make God's intentions visible as mediated by humans. Being actual means being no longer virtual, which is an inferior state, ultimately brute and shapeless nature. To Bacon, therefore, natural history and the history of technology are but one and the same natural history. This is the dawn of empiricism, of the natural and the applied sciences. Previously to this period, human intervention was also necessary for passive virtuality to be actual, but only in a process of cognition, not of practical action, as, for instance, in Aristotle's theory of the mind, as presented in his psychology, De anima (ca. $450 \mathrm{BC}$ ).

In this work, Aristotle interprets our mind as an organ different from our more specialized senses in its capacity to perceive all forms and to reflect upon them. Our mind has a double structure. It is a receptive mind and a reflective mind, and this twofold nature constitutes the virtuality of the mind. The mind is empty but not passive. It is not a tabula rasa. In this context a temporal dimension is involved: first virtual and unspecified, then actual and specified. Here we have a premeditation of the notion of virtuality later developed in the applied sciences and planning processes seen as finite processes developing from a plan to a result.

This approach can be found, for instance, in Abbé Morelly's utopian city, as described in his Code de la nature (1755). Nature is a passive, quantitatively constituted, and ordered harmony of proportions. Through human intervention, this harmony may be transposed to other areas and thereby realized or actualized, for instance, when the harmonious layout of a city, irrespective of its location, mirrors the harmonious, measurable, and quantifiable proportions of nature. Here, and in contrast to Aristotle and the classical concept of genius loci, the 
form defines the site - Athens is a form developed on a virtual, natural site, Brasilia is a form transposed and forced upon an arbitrary place, its virtuality being its plan, as drawn by urbanists and developers, just like the urban grid of New York invented in 1811 before any sensible person could imagine that Manhattan could be the site of a proper city (cf. Glaab, Brown 1983: ch. 12).

\section{Neutral virtuality}

A third meaning of virtual, the neutral one has grown from modern science, first from Newtonian mechanics and the theory of optics that is part of it and later also from nuclear physics. Here, terms like 'virtual image', 'virtual work', or 'virtual state' refer to theoretical constructs that have no empirical status whatsoever outside the language of their theories. 'Virtual work', e.g., is a theoretical construction of the infinite number of hypothetical states that a moving object passes through from one position to another according to the laws of mechanics. These states cannot be singled out and or observed. They are simply identical with their mathematical formula, a calculus, and have no other identity.

The 'virtual image', too, is a construct, according to the laws of optics. An image is virtual and not real if it looks as if it comes from another place or object than that from which the rays really comes. If you look at a stick in water, for instance, it looks broken. The linear prolongation above the water surface from the part of the stick that is below the surface will constitute a virtual image. The 'virtual state' of 'virtual particles' refers to theoretically constructed particles used to explain what is going on between charged particles. "They [...] are not in the real state, i.e., directly observable, they are constructs to enable the phenomenon to be explained in terms of quantum mechanics" (Isaacs et al. 1991: s. v.).

In all such instances the virtual is opposed to what is real, and virtuality is not bound to any active force or any passive receptivity of anything as in the first two instances of virtuality. Thus, there is no change from a virtual to an actual or real state of things. Virtuality is not a property of anything, it is exclusively bound to the medium that makes it manifest, be it a theory, a formal language, or an optical piece of equipment. Virtuality belongs to the symbolic structure of the 
semiotic system involved and not to the referential dimension of signs, as in the case of Aristotle's active, or Bacon's passive virtuality.

The third version of virtuality interprets the pair 'virtual' vs. 'actual or real' as exclusive opposites like in the passive sense of virtuality, but it does not entail any ontological assumptions that cannot be deduced from the medium in question. The relation between virtual and actual or real, therefore, is arbitrary or, to phrase it slightly differently, it is media determined all the way through. Reality is simply the sum total of all empirical phenomena as far as they follow the laws of physical mechanics, of optics, or whatever a formal language can define as real.

In the active and the passive conception of virtuality, however, ontological assumptions are important in their own right. In the first case, reality is a synthesis of actuality and virtuality in a selfgoverning process. In the second case, matter is empty and therefore part of a process governed by the forms that are imposed on it and it is precisely its emptiness that makes it possible for forms to act as forms. In the third case, matter, as empirical reality is neither processual nor empty, but dead material brought to life, as it were, through theoretically based mental or material constructs. According to John Locke and the materialist philosophers of the 17th and 18th centuries, the mind is also empty and dead in this sense. It has no structure of its own but what is imposed upon it through the senses. Ideas are understood from theoretical models constructed on the basis of causal relations between material things.

\section{Virtual reality}

It seems clear to me that 'virtual reality' in the sense of computerized gloves and glasses or in terms of powerful tools for the construction of scenarios in the planning of bridges or landscapes are virtual in the third sense, absorbing the second, the passive one, but in a deontologized sense. There is a temporal relation between virtual and actual, as in the case of the passive virtuality - from a scenario which is first to a reality which is second - , but the relation between them is arbitrary, as in the case of the neutral virtuality based, as it is, on an explicit methodology of semiosis. In neither of the cases the virtual and the actual are levels of the same reality: virtuality is nonreal as a hypo- 
thetical sketch on certain media specific conditions, actual reality is the end result.

We need to reintroduce the first, the active sense, but without of its mainly teleological metaphysics. My claim is that it is both necessary in relation to nature and possible in relation to theory and practice to bring about this reintroduction. However, it is not a choice that goes without saying. It is a matter of theory, definition, and decision, because everyday language does not make any choice for us.

I find the combinations of virtuality and reality equally confusing both outside and inside the casual context of everyday communication. The problem is that we cannot return to a prescientific notion of virtuality, e.g., to the one of Bacon. The technology that makes the relation between virtuality and reality arbitrary to a certain extent is simply present everywhere around us. Our entire social structure, materially and symbolically, presupposes it. Bacon is right: natural and technological history is the same history. But nevertheless, I will try to restore the ontological dimension of the notion of virtuality lost in the passive and neutral conception but without adopting the metaphysics that usually goes with it.

In this respect, it is worth while remembering that the classical notions of reality have had two important characteristics: on the one hand, reality is not real without human participation (but not necessarily human control). On the other hand, it is not anthropocentric in the modern sense of utilitarianism with human control and human purposiveness as its core. In contrast, post-Newtonian reality obeying natural laws of mechanics is indifferent to human participation. If humans are involved, they are real in the same sense as all other things: the mind functions according to material causality, and the body is a particular kind of bio-mechanical machine. The contrast to this conception is an anthropocentric version of reality, seeing reality as an environment around our perceptions and mental projections - an Umwelt. This viewpoint is a consequence of Kantian and Romantic philosophy leading to phenomenology and, for instance, Jakob von Uexküll's biosemiotics. This basic epistemological anthropocentrism is not bound to any utilitarianism, but is a way of grasping bodily human presence as fundamentally mediated by perception, cognition, and symbols.

It is evident that the gadget version of virtual reality constructs and also presupposes an anthropocentric space, whereas in the virtual reality scenarios for planning of bridges, landscapes etc. human presence makes no difference to the functioning of the scenario as a technical 
construct. Humans are just another component or factor. We may say that plus minus human presence indicates two possible worlds at the same ontological level. However, if we wish to draw this difference, a basic difference in our understanding of reality, the distinction will have to be imposed on the neutral definition of virtuality which is the basic definition in a technologically hyperdetermined human reality. In order to propose an ontologically loaded but nonutilitarian conception of virtuality, I will make a detour into fiction and literature before I return to nature.

\section{Possible worlds and human location}

The American literary theorist Marie-Laure Ryan has developed the notion of possible worlds in such a direction. In her Possible Worlds, Artificial Intelligence, and Narrative Theory (1991) she does not use the term virtuality, but reality and actuality, instead. She defines a "system of reality" as a set of distinct worlds. "The system has a modal structure and forms a modal system if it comprises a central world surrounded by satellite worlds. The center of a model system is its actual world, the satellites are alternative possible worlds" (Ryan 1991: vii). The modality is of course expressed in the "if". "The actual world, the center of our system of reality, is the world where I am located" (Ryan 1991: vii).

Now, an alternative possible world is one of the other worlds in the modal system. The textual reference world is the world for which a given text claims facts (e.g., a set of quantitative data, such as, 'King Lear has three daughters'). To Ryan, a text is any media specific presentation of a world (we cannot talk about representations because we are dealing with possible worlds). The textual actual world is an image of the textual reference world proposed by the text in pictures, numbers, letters, gestures, etc. Ryan also makes other distinctions relevant for her narrative theory that I have to omit here.

The main point for me is not the logico-technical definition of possible worlds, but her claim that the actual world is part of, and determines, reality as a set of distinct worlds, whether possible or not. It is the basic modality of the system, as Ryan puts it. The possibility for humans to be located is essential — with symbolic means, e.g., the deictic functions of language and other semiotic systems, or material means for bodily location, e.g., walking, working, building. To the act 
of location belongs the very production of plans, projections, possibilities, alternatives, etc. in any medium. Reality is the whole set of possible worlds around an actual world. Making plans for a future state of affairs is a way of locating oneself in the actual world, of changing positions etc. Planning is not the process of presenting something that is nonreal, but may eventually become real in the future. It is an intervention in the system of reality. Virtuality, is then, so to speak, the localizability of a phenomenon, its possibility to be related to the actual world.

Ryan goes a step further in claiming that the actual world is not only the world in which I am located but "from which I speak" (Ryan 1991: 17), thereby linking inextricably the notion of actuality to the production of symbols, suggesting an "indexical theory of actuality [where] speech acts always take place in the actual world for their participants" (Ryan 1991: 22).

Here, the bottom line is that virtuality is a human construction in any material medium, language, pictures, machines - by which humans anchor themselves in an actual world. Virtuality is a semiotic process. Therefore, like any other semiotic process virtuality related to human participation cannot work without ontological assumptions concerning the status of the sign and its object as, for instance, in Charles Sanders Peirce's semiotically adapted realism. When virtuality is put to work it works mainly through deictic functions by which we anchor ourselves in a bodily universe, thus embedding the different possible worlds from the point of view of an actual world. Virtuality is first of all a semiotic process through which we produce human location, and it is only accidentally bound to a specific - and spectacular or sophisticated - technology or other specific material media. The deictic symbolism is intimately and most fundamentally related to our bodily presence.

The otherwise stimulating book by Thomas Pavel, Fictional Worlds (1986), presents possible worlds as a system of parallel worlds, but not, as Ryan does, as semiotic process of location. This is another useful conception of fiction and literature. It makes fiction accessible as a specific human — and not just logically analyzable activity based on a human dependence on semiotic systems and thereby on an anthropocentrism more basic than utilitarian systems of human interest.

Another characteristics of virtuality is the one pointed out by Lubomir Doležel in his Heterocosmica: Fiction and Possible Worlds (1998: 222): "Fiction thrives on the contingency of worlds emphati- 
cally asserted by the idea of possible worlds: every world and every entity in the world could be or could have been different from what it is". With this in mind, our view of virtuality can be stretched a little, and we arrive at the following definition: virtuality is a human construction - in any material medium - by which humans anchor themselves in an actual world in view of its possible changes. Virtuality, then, carries with it the conditions and limits of the possible changes.

Nature, in this context, is an aspect of our actual world with specific conditions and limits for changes through human intervention. We cannot have a relation to nature without constructions, without fictions, without virtualities.

In different historical epochs, the phenomenon, which we see as virtual, tends to change. For Aristotle, the place or the site constituted the basic virtuality of space. For a modern planner, the model or plan or the scenario is the basic virtual unit explicating the conditions and limits of the natural site. Actualizing or realizing a virtuality is then to find ways, conditions, etc. for locating the plan or the model in an actual world, but it is not simply to make a reality as close as possible to the picture or the model. It is a tool for location and participation in our actual world. Virtual reality articulates the conditions and limits for our references, our means of expression, and our communicative understanding.

In a certain sense, then, we have returned to Aristotle, namely in the sense that virtual and actual are not fixed properties of certain phenomena, but relative stages of process. An urban plan is just as virtual as the ground to be built on and both are, as virtual phenomena, part of an actual world. However, once built, the urban environment is itself virtual in relation to what may happen in and with the city. Virtual and actual constitute links in a long chain. They are different levels of one reality. There is no way of saying that a plan, which was once not real, has finally become realized, and then it is over. The plan has always been real in the sense that it is a possible world in a given system of reality. This is the basic difference to Aristotle: the virtual and the actual are tied up with our decision-making and sign production. Ecological decision-making and sign production is but one type of process framed by virtuality.

Being virtual in this sense means having the power to enter in this process, not simply to change from plan to reality. Therefore, if a plan is virtual in this sense it will take into account continuously changing relations between virtuality and actuality, following a product from 
the origins of its raw material to its ultimate destruction. If a plan is virtual only in the passive or neutral sense, it only indicates the transformation from plan to thing or from unformed material to final product, and thereafter God knows what might happen to the resulting waste or byproducts. To see virtuality, as suggested, unites virtuality once more with virtue. It implies that our relation with nature is an ongoing process in which we participate. It makes us responsible all the way through, with virtual constructions to spell out - verbally, visually, or otherwise - for the conditions and limits of our participation. It obliges us constantly to locate and relocate ourselves in the actual world and the nature we live in.

\section{References}

Aristoteles 1921. Politica. The Works of Aristotle 10. Oxford: Clarendon. Aristoteles 1931. De anima. The Works of Aristotle 4. Oxford: Clarendon. Augustinus 1955. Vom Gottesstaat. 1-2. Zürich: Artemis. Bacon, Francis 1994. Novum Organon. Chicago: Open Court.

Cicero, Marcus Tullius 1967. De natura deorum. London: Loeb.

Doležel, Lubomir 1998. Heterocosmica: Fiction and Possible Worlds. Baltimore: John Hopkins University Press.

Glaab, Charles; Brown, A. Theodore 1983. A History of Urban America. 3rd ed. New York: Macmillan.

Isaacs, Alan et al. 1991. Concise Science Dictionary. Oxford: Oxford University Press.

Locke, John 1979. An Essay Concerning Human Understanding. 2 vols. New York: Dover.

Morelly, Abbé 1950. Code de la nature. Paris: Raymond Clavreuil.

Pavel, Thomas 1986. Fictional Worlds. Cambridge, Mass.: Harvard Univ. Press.

Ryan, Marie-Laure 1991. Possible Worlds, Artificial Intelligence, and Narrative Theory. Bloomington: Indiana University Press.

\section{Природа между фактом и вымыслом: о виртуальной реальности}

В статье модное понятие виртуальности и виртуальной реальности ставится в концегтуальный и исторический контекст, который позволяет его рассматривать в семиотической перспективе. Виртуальность связана с классическим понятием фикциональности, как в смысле вымышлен- 
ности, так и в смысле обманчивости. Исторически можно выделить активную, пассивную и нейтральную версии концепта. Это понятие подвергалось переинтерпретации и как вариант семиотических процессов дейксиса. В отношении к природе - сценарии, прогнозы, гипотезы и т.д. - виртуальность представляется скорее в качестве средства прикрепления человека к природе, чем в качестве средства конструирования ирреального универсума, отделенного от природы.

\section{Loodus fakti ja väljamõeldise vahel: tähelepanek virtuaalse reaalsuse kohta}

Artiklis asetatakse moekas virtuaalsuse ja virtuaalse reaalsuse mõiste kontseptuaalsesse ja ajaloolisse konteksti, mis muudab selle semiootilises perspektiivis produktiivseks. Virtuaalsus on seotud klassikalise fiktsionaalsuse mõistega, nii selle väljamõelduse kui petlikkuse mõttes. Ajalooliselt on eristatavad kontsepti aktiivne, passiivne ja neutraalne versioon. Mõistet on ümber interpreteeritud kui deiksise semiootiliste protsesside varianti. Seoses loodusega — stsenaariumide, prognooside, hüpoteesidega jne. — nähakse virtuaalsust pigem inimsubjekti loodusesse kinnistavana, kui loodusest lahutatud ebareaalset universumi konstrueerivana. 